\title{
Agrobacterium-mediated transformation of kabocha squash (Cucurbita moschata Duch) induced by wounding with aluminum borate whiskers
}

\author{
Yoshihiko Nanasato $\cdot$ Ken-ichi Konagaya \\ Ayako Okuzaki $\cdot$ Mai Tsuda $\cdot$ Yutaka Tabei
}

Received: 24 January 2011/Revised: 16 February 2011/Accepted: 24 February 2011/Published online: 13 March 2011

(C) The Author(s) 2011. This article is published with open access at Springerlink.com

\begin{abstract}
An efficient genetic transformation method for kabocha squash (Cucurbita moschata Duch cv. Heiankogiku) was established by wounding cotyledonary node explants with aluminum borate whiskers prior to inoculation with Agrobacterium. Adventitious shoots were induced from only the proximal regions of the cotyledonary nodes and were most efficiently induced on MurashigeSkoog agar medium with $1 \mathrm{mg} / \mathrm{L}$ benzyladenine. Vortexing with $1 \%(\mathrm{w} / \mathrm{v})$ aluminum borate whiskers significantly increased Agrobacterium infection efficiency in the proximal region of the explants. Transgenic plants were screened at the $\mathrm{T}_{0}$ generation by sGFP fluorescence, genomic PCR, and Southern blot analyses. These transgenic plants grew normally and $\mathrm{T}_{1}$ seeds were obtained. We confirmed stable integration of the transgene and its inheritance in $\mathrm{T}_{1}$ generation plants by sGFP fluorescence and genomic PCR analyses. The average transgenic efficiency for producing kabocha squashes with our method was about $2.7 \%$, a value sufficient for practical use.
\end{abstract}

Communicated by K. Toriyama.

Y. Nanasato $\cdot$ K. Konagaya $\cdot$ A. Okuzaki $\cdot$ M. Tsuda .

Y. Tabei $(\bowtie)$

Division of Plant Sciences, National Institute of Agrobiological

Sciences, 2-1-2 Kannondai, Tsukuba, Ibaraki 305-8602, Japan

e-mail: tabei@affrc.go.jp

Present Address:

K. Konagaya

Forest Bio-Research Center,

Forestry and Forest Products Research Institute,

3809-1 Ishi, Juo, Hitachi, Ibaraki 319-1301, Japan
Keywords Agrobacterium - Cucurbita moschata . Regeneration · sGFP · Transformation · Whiskers

\section{Introduction}

The genus Cucurbita includes five important cultivated species: C. argyrosperma Huber, C. ficifolia Bouché, C. maxima Duchesne, C. moschata Duchesne, and C. pepo L. Global production of the Cucurbita genus reached 21 million tons in 2009 (http://faostat.fao.org). Cucurbita crops are consumed as food, incorporated into processed foods, and used as animal feed. In Japan, some Cucurbita species are used as rootstocks for cucumber, melon, and watermelon (Oda 2008) to induce resistance to diseases and insect pests, to provide higher stress tolerance, to provide higher yields, and to improve fruit quality (Edelstein 2004). In addition, the Cucurbita genus has the unique ability to take up organic xerobiotics and persistent organic pollutants from the soil (Hulster et al. 1994; Inui et al. 2008; Otani et al. 2007; White et al. 2003), and thus, helps in phytoremediation.

Genetic engineering can improve crops by exploiting useful genes and engineering transgenic plants with desirable properties, such as disease resistance. Several reports of genetic transformation of members of the family Cucurbitaceae, including Cucumis melo (Akasaka-Kennedy et al. 2004; Wu et al. 2009), Cucurmis sativas (Tabei et al. 1998; He et al. 2006; Vasudevan et al. 2007), Citrullus lanatus (Akashi et al. 2005; Choi et al. 1994), and Lagenaria siceraria (Han et al. 2005) are present. However, molecular analysis of the Cucurbita genus has been hampered by a lack of effective transformation methods. To date, only two transformation methods have been reported (Tricoli et al. 1995; Shah et al. 2008). 
Tricoli et al. (1995) obtained transgenic C. pepo with virus resistance, but the details of their method or the transformation efficiency remain unknown. Shah et al. (2008) obtained transgenic C. pepo via shoot organogenesis, but efficiency of their method was only $0.7 \%$. Regeneration via embryogenesis from cotyledons was reported by Jelaska (1972) and recently, other groups have also succeeded in inducing shoot organogenesis in C. pepo (Ananthakrishnan et al. 2003; Kathiravan et al. 2006), C. maxima (Lee et al. 2003), and C. moschata (Zhang et al. 2008) using cotyledonary explants. Reports of transformation of C. maxima or C. moschata are absent, although some varieties of C. moschata are more tolerant to various abiotic stresses, diseases, and insect pests than other members of the Cucurbita genus, and thus, are of great research interest.

Cucurbita species are susceptible to Agrobacterium infection (Smarrelli et al. 1986; Toppi et al. 1997), and studies have shown that wounding enhances Agrobacterium-mediated transformation efficiency (Curuk et al. 2005; Yamada et al. 2010). Whiskers, needle-like crystals with very high tensile strength, have often been used for direct gene transfer into callus tissues (Asad et al. 2008; Mizuno et al. 2004; Petolino et al. 2000). In this study, we report an efficient method for transformation of C. moschata Duch cv. Heiankogiku. We found that wounding explants with aluminum borate whiskers is a critical step for efficiently producing transgenic pumpkins. The average transformation efficiency was increased to about $2.7 \%$ with this method, making it suitable for practical use. This is the first report of an efficient transformation via adventitious shoot organogenesis in C. moschata Duch.

\section{Materials and methods}

Preparation of cotyledonary explants

Seeds of C. moschata (cv. Heiankogiku) were purchased from Takii \& Co., Ltd. (Kyoto, Japan). Seed coats were removed with a scalpel and forceps. The peeled seeds were sterilized for $10 \mathrm{~min}$ using $1 \%$ (w/v) sodium hypochlorite and one drop of Tween 20 and rinsed five times with sterile distilled water. The sterilized seeds were germinated at $28^{\circ} \mathrm{C}$ in the dark for 1 day on shoot-inducing (SI) Murashige-Skoog (MS) medium (Murashige and Skoog 1962) with $1 \mathrm{mg} / \mathrm{L}$ 6-benzyladenine (BA), and $0.8 \%(w / v)$ agar. All media were autoclaved at $121^{\circ} \mathrm{C}$ for $15 \mathrm{~min}$ and their $\mathrm{pH}$ was adjusted to $5.7-5.8$ prior to the addition of agar. Cotyledons were excised from post-germination seedlings using a stereoscopic microscope, taking care not to remove the cotyledonary nodes (Fig. $1 \mathrm{a}, \mathrm{b}$ ). The cotyledons were first cut in half crosswise, and the distal regions were discarded. The explants were then cut into two longitudinal sections (Fig. 1c) and placed with their abaxial sides up in a 9-cm petri dish containing SI medium. They were precultured for 1 day at $25^{\circ} \mathrm{C}$ in the dark before being transformed with Agrobacterium.
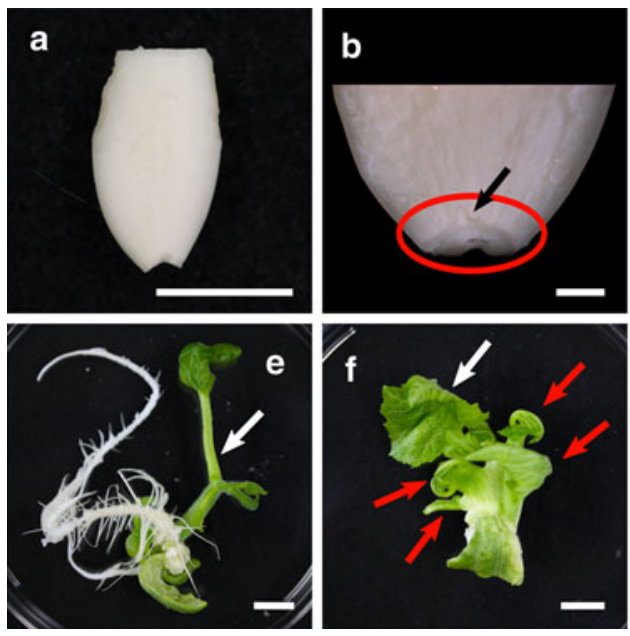

Fig. 1 Shoot regeneration from cotyledonary explants of $C$ moschata cv. Heiankogiku a A cotyledon detached from a hypocotyl. Bar, $5 \mathrm{~mm}$. b Proximal region of a cotyledon. The red circle and black arrow indicate the junction of the hypocotyl and cotyledon, and the shoot apex, respectively. Bar, $1 \mathrm{~mm}$. c Preparation of cotyledonary explants. Red arrows indicate the proximal regions of the cotyledons used as explants; arrowheads indicate the distal regions. Bar, $5 \mathrm{~mm}$. d A magnified explant. Note that the junction between the cotyledon

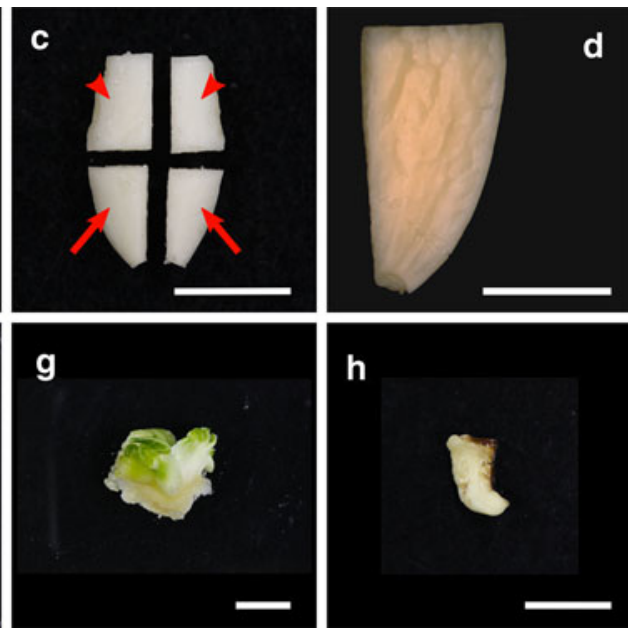

and hypocotyl is intact. Bar, $3 \mathrm{~mm}$. e-h Explants grown under MS medium with $0.1 \mathrm{mg} / \mathrm{L} \mathrm{BA}(\mathbf{e}), 1.0 \mathrm{mg} / \mathrm{L} \mathrm{BA}(\mathbf{f}), 4.0 \mathrm{mg} / \mathrm{L} \mathrm{BA}(\mathbf{g})$, and $2.0 \mathrm{~m} / \mathrm{L}$ BA plus $1.0 \mathrm{mg} / \mathrm{L} \mathrm{ABA}$ (h). The explants were incubated in the medium described for 37 days. The white arrows in (e) and (f) indicate shoots developed from the shoot apex, and the red arrows in (f) indicate shoots induced by shoot organogenesis, respectively. Bars, $(\mathbf{e}-\mathbf{h}) 10 \mathrm{~mm}$ 
Bacterial strain and binary vector

Agrobacterium tumefaciens strain EHA105 harboring the binary vectors pIG121-Hm (Akama et al. 1992), pIG-sGFP, and pGFP-S65C was used for transformation (Fig. 2). The pIG-sGFP vector carried a $\beta$-glucuronidase gene $(G U S)$ with a castor bean intron and synthetic green florescent protein gene $(s G F P)$ with serine at position 65 replaced with threonine (S65T) (Chiu et al. 1996). The pGFP-S65C vector carried a $s G F P$ with serine at position 65 replaced with cysteine (sGFP-S65C) by site-directed mutagenesis under the control of the constitutive promoter CaMV35S, and was constructed by replacing GUS from pIG121-Hm with $s G F P$ S65C. Agrobacterium was cultured with $10 \mathrm{ml}$ of LuriaBertani medium ( $\mathrm{pH} 5.2$ ) containing $50 \mathrm{mg} / \mathrm{L}$ kanamycin, $25 \mathrm{mg} / \mathrm{L}$ chloramphenicol, $25 \mathrm{mg} / \mathrm{L}$ rifampicin, and $20 \mu \mathrm{M}$ acetosyringone at $28^{\circ} \mathrm{C}$ until the optical density at $600 \mathrm{~nm}$ reached $0.4-0.8$. The bacterial culture was centrifuged and resuspended in inoculation medium (IN) containing SI liquid medium with $500 \mu \mathrm{M}$ acetosyringone, and final concentration of Agrobacterium (measured by optical density at $600 \mathrm{~nm}$ ) was adjusted to 0.1 . Prior to inoculation, the Agrobacterium culture was resuspended by gentle shaking at $28^{\circ} \mathrm{C}$ for $1-2 \mathrm{~h}$ to ensure efficient induction of vir genes.

Wounding of explants

Aluminum borate whisker powder (Alborex Y; Shikoku Chemicals Corporation, Kagawa, Japan, Suganuma et al.
1990) was sterilized prior to use by autoclaving. Approximately 100 explants were added to a 50-ml centrifuge tube containing $20 \mathrm{ml}$ of whisker slurry in SI liquid medium under aseptic conditions. The tube was then vortexed for 30 min using a vortex mixer (Vortex Genie 2 with a 29-37 mm Tube Foam Inserts; Scientific Industries, Inc, Bohemia, NY).

Inoculation, co-cultivation with Agrobacterium, selection, and regeneration of transgenic plants

Wounded explants were resuspended in the Agrobacterium culture and shaken gently for $10 \mathrm{~min}$ at room temperature. Excess liquid was removed using sterilized filter papers, and wounded explants were co-cultured on three pieces of filter paper (Ozawa 2009) moistened with $5.5 \mathrm{ml}$ of IN medium at $25^{\circ} \mathrm{C}$ in the dark for 3 days. After co-cultivation, explants were washed five times with sterilized distilled water and transferred to a selection medium containing SI agar with $10 \mathrm{mg} / \mathrm{L}$ meropenem (Ogawa and Mii 2007) and $50 \mathrm{mg} / \mathrm{L}$ kanamycin, placed in the growth chamber maintained at $25^{\circ} \mathrm{C}$, a $16 / 8 \mathrm{~h}$ (light/dark) photoperiod with white fluorescent lamps. Explants were subcultured on fresh media after a 2 -week interval. Following culture on the selection medium for 4-6 weeks, the regenerated shoots were excised and transferred to shoot elongation (SE) medium containing half-strength MS medium with $0.1 \mathrm{mg} / \mathrm{L} \mathrm{BA}, 0.8 \%$ agar, $10 \mathrm{mg} / \mathrm{L}$ meropenem, and $50 \mathrm{mg} / \mathrm{L}$ kanamycin. Non-chimeric transgenic lines were selected via axillary bud culture in SE medium.

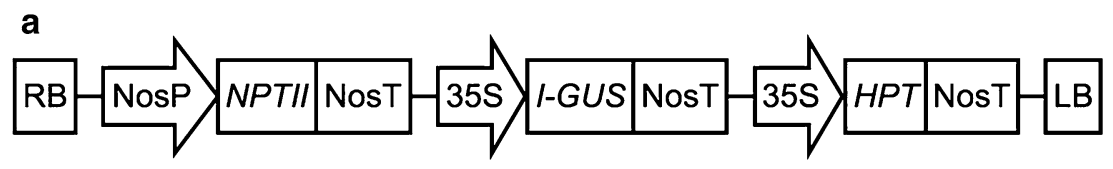

b
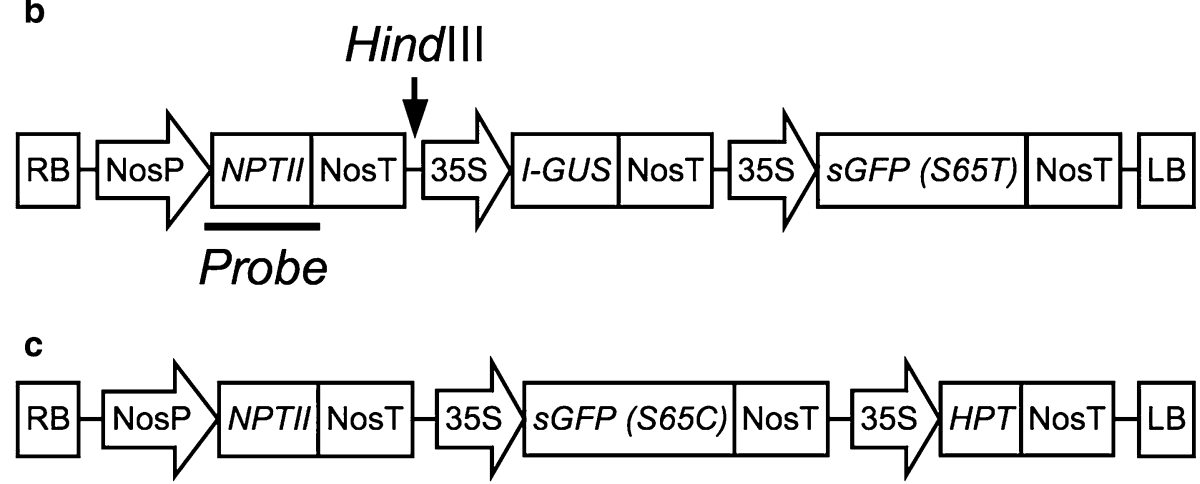

Fig. 2 Schematic diagrams of the T-DNA region of the binary vectors used in this study a pIG121-Hm b pIG-sGFP c pGFP-S65C. A restriction site of HindIII and a DNA fragment of NPTII used as a probe for Southern blot analysis in pIG-sGFP were indicated, respectively. $R B$ right border, Nos $P$ nopaline synthase promoter, NPTII neomycin phosphotransferase, 35S CaMV 35S promoter,
I-GUS $\beta$-glucuronidase containing a castor bean intron, NosT nopaline synthase terminator, HPT hygromycin phosphotransferase, $L B$ left border, $s G F P$ (S65T) and $s G F P$ (S65C) synthetic green fluorescent protein with serine at position 65 replaced with threonine or cysteine, respectively 
Rooting plants were acclimatized and grown in an enclosed greenhouse.

Visible marker assay

Histochemical GUS assays were performed on cotyledonary explants from day 7 after the elimination of Agrobacterium. The GUS-staining solution containing $100 \mathrm{mM}$ potassium phosphate buffer $(\mathrm{pH} 7.0), 10 \mathrm{mM}$ ethylenediaminetetraacetic acid, $0.1 \%$ Tween $20,5 \mathrm{mM}$ potassium ferricyanide, $5 \mathrm{mM}$ potassium ferrocyanide, $20 \%(\mathrm{w} / \mathrm{v})$ methanol, and $1 \mathrm{mM} 5$-bromo-4-chloro-3-indoyl- $\beta$-D-glucuronide was introduced into the cotyledonary explants by two sessions of vacuum infiltration for $7.5 \mathrm{~min}$. The tissues were incubated overnight at $37^{\circ} \mathrm{C}$. After staining, tissues were rinsed with $70 \%$ ethanol to remove chlorophyll.

sGFP fluorescence from transgenic plants was observed using the Leica MZ16FA epifluorescence stereomicroscope (Leica Microsystems GmbH, Wetzlar, Germany) equipped with a light source, $100 \mathrm{~W}$ mercury bulb, and a FITC/GFP filter set with a 480-nm excitation filter and a 510-nm longpass emission filter producing blue light.

DNA isolation and polymerase chain reaction (PCR) analysis

For PCR analysis, genomic DNA from leaves of C. moschata plants was extracted as described previously (Edwards et al. 1991). Primer pairs used for amplifying sGFP were $5^{\prime}$-ctgggtaccatggtgagcaagggcgaggag- $3^{\prime}$ and $5^{\prime}$-gcgactagtttacttgtacagctcgtccat- $3^{\prime}$; those for amplifying NPTII were $5^{\prime}$-ccgcttgggtggagaggctattc- $3^{\prime}$ and $5^{\prime}$-ccagccg gccacagtcgatgaat $-3^{\prime}$; those for amplifying $\operatorname{HrcA}$ were $5^{\prime}$-ca tcgtcgaaggttatctcgatacg- $3^{\prime}$ and $5^{\prime}$-tataatcgaccatcggtacga tacg-3'; and those for amplifying elongation factor $1-\alpha$ (EF1 $\alpha$ : GenBank accession No. AB615454) were 5'-agacc accaagtactactgcac- $3^{\prime}$ and $5^{\prime}$-ccaccaatcttgtacacatcc- $3^{\prime}$. PCR amplification was performed under the following conditions: $94^{\circ} \mathrm{C}$ for $2 \mathrm{~min}, 30$ cycles at $94^{\circ} \mathrm{C}$ for $30 \mathrm{~s}$, at $63^{\circ} \mathrm{C}$ for $30 \mathrm{~s}$, and at $72^{\circ} \mathrm{C}$ for $1 \mathrm{~min}$, and a final extension step at $72^{\circ} \mathrm{C}$ for $7 \mathrm{~min}$. PCR products were separated on $1.5 \%$ agarose gel and visualized by ethidium bromide staining.

\section{Southern blot analysis}

Genomic DNA was isolated from young, developing leaves by a DNAs-ici!-P kit (Rizo inc. Tsukuba, Japan), and RNA was degraded using RNase A. Twenty $\mu \mathrm{g}$ of genomic DNA was digested with HindIII, separated on a $0.7 \%$ agarose gel, and transferred to nylon membranes positively charged (Roche Diagnostics, Indianapolis, IN) with 20x saline sodium citrate buffer. A digoxigenin (DIG)-labeled DNA probe specific for the NPTII coding sequence was used for
Southern hybridization and detection was performed according to the manufacturer's instructions (Roche Applied Science, Penzberg, Germany).

\section{Results and discussion}

Effect of plant hormones on regeneration

In a preliminary examination, we screened 16 varieties of Cucurbita species for differences in shoot organogenesis (data not shown) and selected $C$. moschata cv. Heiankogiku. We then examined the effect of each region of the cotyledonary explant detached from the cotyledonary nodes on adventitious regeneration (Fig. 1a, b). Excision of the hypocotyl fragment led to loss of direct shoot development (data not shown), which is in agreement with recent reports of direct regeneration in other Cucurbita species (Ananthakrishnan et al. 2003; Kathiravan et al. 2006; Lee et al. 2003; Zhang et al. 2008). We also found that after culturing on SI medium, the proximal region of the cotyledonary node (Fig. 1c, d) was capable of shoot regeneration. Thus, we used proximal regions of the cotyledons with hypocotyl fragments as explants in the following experiments. Tendency of diminishing regeneration efficiency at the distal regions of the cotyledons has also been reported previously (Tabei et al. 1993). We next examined the effect of several plant hormone concentrations on adventitious shoot regeneration (Table 1). Use of $1 \mathrm{mg} / \mathrm{L} \mathrm{BA}$ significantly increased shoot regeneration with a score of $66.9 \%$ (Table 1; Fig. 1f), which is similar to results reported previously (Ananthakrishnan et al. 2003; Lee et al. 2003; Zhang et al. 2008). Furthermore, $0.1 \mathrm{mg} / \mathrm{L}$ BA induced shoot elongation, but this elongation appeared to develop because of the tendency of the shoot apex to elongate, and not from shoot organogenesis. Furthermore, a lower BA concentration also stimulated root formation, suggesting that the endogenous cytokinin/auxin ratio was too low to induce shoot organogenesis on such media (Fig. 1e). In contrast, Shah et al. (2008) succeeded in inducing shoot organogenesis from summer squash using $0.05 \mathrm{mg} / \mathrm{L} \mathrm{BA}$ without root induction. The difference in results may be attributed to the different species characteristics or to the fact that they used shoot tip segments excised from 4- to 5-day-old seedlings. It appeared that elongated shoots were not regenerated adventitious shoots but elongations of axial buds. Using $4 \mathrm{mg} / \mathrm{L} \mathrm{BA}$ often led to severe vitrification and abnormal shoot formation (Fig. 1g), and in such cases the adventitious shoots were not elongated. Although the combination of BA and abscisic acid (ABA) was efficient in inducing shoot regeneration in cucumber (Tabei et al. 1998), this combination often led to severe growth inhibition and browning 
Table 1 The effect of plant growth hormones on organogenesis of cotyledonary explants in C. moschata cv. Heiankogiku

\begin{tabular}{lllcc}
\hline Shoot induction medium $^{\mathrm{a}}$ & $\begin{array}{l}\text { Total no. of } \\
\text { explants }\end{array}$ & $\begin{array}{l}\text { Regeneration } \\
\text { efficiency }(\%)^{\mathrm{b}, \mathrm{e}}\end{array}$ & $\begin{array}{l}\text { Shoot number } \\
\text { per explant }\end{array}$ & $\begin{array}{l}\text { Root induction } \\
\text { efficiency }(\%)^{\mathrm{d}, ~ e}\end{array}$ \\
\hline $0.1 \mathrm{mg} / \mathrm{L} \mathrm{BA}$ & 107 & $62.6 \pm 6.0$ & $1.27 \pm 1.19$ & $34.4 \pm 20.7$ \\
$1.0 \mathrm{mg} / \mathrm{L} \mathrm{BA}$ & 106 & $66.9 \pm 9.4$ & $1.91 \pm 1.66$ & $0.3 \pm 0.6$ \\
$4.0 \mathrm{mg} / \mathrm{L} \mathrm{BA}$ & 110 & $50.2 \pm 6.0$ & $1.0 \pm 1.17$ & 0 \\
$2.0 \mathrm{mg} / \mathrm{L} \mathrm{BA}+1.0 \mathrm{mg} / \mathrm{L} \mathrm{ABA}$ & 103 & $35.2 \pm 24.2$ & $0.84 \pm 1.30$ & 0 \\
\hline
\end{tabular}

${ }^{a}$ All media used in this experiment contained $30 \mathrm{~g} / \mathrm{L}$ sucrose, MS salts, vitamins, and $0.8 \%$ agar

${ }^{\mathrm{b}}$ Regeneration efficiency $=($ Number of explants with one or more shoots/total number of explants $) \times 100$

$c$ Average number of shoots induced in each explant

${ }^{\mathrm{d}}$ Root induction efficiency $=$ (Number of explants with one or more roots/total number of explants $) \times 100$

e Each value represents the mean \pm SD from three independent experiments
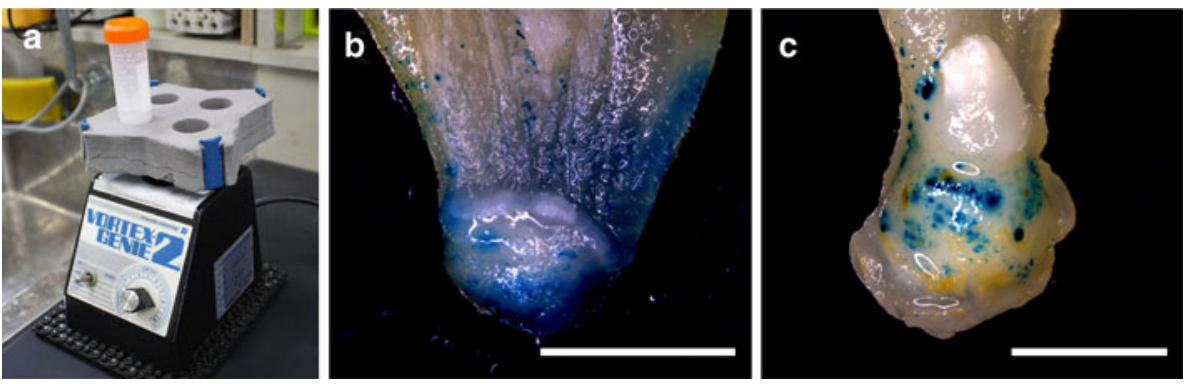

Fig. 3 Agrobacterium-mediated transformation a vortexing apparatus. Vortex Genie 2 with an adaptor for a 50-ml centrifuge tube. b, c GUS activity in proximal region of explants wounded using a

of kabocha squash explant edges (Fig. 1h). Therefore, we concluded that $1 \mathrm{mg} / \mathrm{L}$ BA was the most effective concentration in a case of using Heiankogiku, and we used this concentration for subsequent genetic transformation experiments.

\section{Improvement of Agrobacterium infection efficiency}

To optimize conditions for efficient Agrobacterium infection, Agrobacterium cultures harboring pIG121-Hm (Fig. 2a) were infected and a GUS assay was performed. Strong GUS activity was observed in the cut regions of the explants; however, infection of the proximal regions of the explants was insufficient. Acetosyringone is an effective activator of vir genes, and it is frequently used for Agrobacterium-mediated transformation in various plant species (Damgaard et al. 1997; Dutt and Grosser 2009; Wang et al. 2009). Therefore, we added $500 \mu \mathrm{M}$ acetosyringone to the co-cultivation medium in an attempt to increase the infection efficiency. However, transformation efficiency in the proximal region remained insufficient. Antioxidants such as L-cysteine (Olhoft and Somers 2001) and ethylene inhibitors such as aminoethoxyvinylglycine (Ezura et al. 2000) also did not significantly increase the infection vortex mixer and whiskers before Agrobacterium infection (b), and in explants that were not wounded before Agrobacterium infection (c). Bars, $5 \mathrm{~mm}$

efficiency in this region (data not shown). We then examined numerous wounding treatments administered to the proximal regions of the explants, namely (1) cutting the area with a scalpel blade, (2) ultrasonic treatment $(150 \mathrm{~kW}$, $1 \mathrm{~min}$, three times), (3) particle bombardment (1,350 psi, $1.6 \mu \mathrm{m}$ gold particle, two shots), (4) scratching the proximal regions of the explants with a flat file, and (5) scratching the proximal region of the explants with carborandom and a cotton swab. Two independent transgenic pumpkin plants were obtained using method (5) (data not shown), but it was time-consuming and the transgenic efficiency was low (two transformants from 612 explants, $0.33 \%)$. No transformants were obtained using other methods.

Production of transgenic plants using aluminum borate whiskers

In an effort to find another method, we used a vortex mixer (Fig. 3a) and "Albolex Y" aluminum borate whiskers (Suganuma et al. 1990), which form white needle-like crystals (10-30 $\mu \mathrm{m}$ in length/0.5-1.0 $\mu \mathrm{m}$ in diameter) with very high tensile strength. Vortexing for $30 \mathrm{~min}$ with $1 \%$ of the whisker suspension dramatically increased the efficiency 
of Agrobacterium infection on proximal region of explants (Fig. 3b), compared with unwounded explants (Fig. 3c). Furthermore, this treatment was rapid and not as labor intensive as method (5).

Agrobacterium harboring the pIG-sGFP and the pGFPS65C binary vectors (Fig. 2b, c) were used for infection, and transgenic plants were screened for sGFP fluorescence. sGFP is a powerful tool for efficiently selecting transgenic plants that develop many escape shoots because GFPintroduced shoots can be easily located without causing any destruction, unlike the GUS staining assay. Initially, we used the pIG-sGFP binary vector containing a $s G F P$ (S65T) expression cassette for transformation. However, sGFP (S65T) fluorescence could be scarcely observed in the mature leaves because strong chlorophyll autofluorescence masked it (data not shown). To observe intense GFP fluorescence in regenerated shoots, serine at position 65 of sGFP was replaced by cysteine (GFP S65C, Reichel et al. 1996), and this was successful even in mature green leaves with high chlorophyll autofluorescence. We vortexed the explants with various concentrations of the whisker suspension $(0,0.1,1$, and $10 \%)$ to find the optimal strength for obtaining transgenic shoots (Table 2). Vortexing for 30 min with $1 \%$ whisker suspension showed the highest transformation efficiency, $2.7 \%$. The $10 \%$ whisker suspension often caused serious damage to the explants and decreased transformation efficiency. Kanamycin was effective for selecting transformed shoots (Fig. 4a), and introduction of $s G F P$ enabled us to locate transgenic shoots (Fig. 4b, c). Repetition of axially bud culture resulted in selection of non-chimeric shoots. Addition of $0.1 \mathrm{mg} / \mathrm{L} \mathrm{BA}$ to MS medium stimulated elongation from the axial buds at

Table 2 The effect of whiskers on transformation efficiency

\begin{tabular}{lllll}
\hline Vortex & Whiskers $(\%)$ & $\begin{array}{l}\text { Total no. } \\
\text { of explants }\end{array}$ & $\begin{array}{l}\text { Total no. of } \\
\text { transformed plants }\end{array}$ & ${\text { Efficiency }(\%)^{\mathrm{b}}}^{\mathrm{a}}$ \\
\hline- & 0 & 257 & 1 & $0.44 \pm 0.77$ \\
+ & 0 & 246 & 3 & $1.33 \pm 2.31$ \\
+ & 0.1 & 253 & 3 & $1.20 \pm 0.18$ \\
+ & 1 & 253 & 7 & $2.73 \pm 1.28$ \\
+ & 10 & 252 & 3 & $1.11 \pm 1.03$ \\
\hline
\end{tabular}

${ }^{a}$ Cotyledonary nodes from seedlings, germinated for 1 day followed by precultured for 1 day, were used as explants. Agrobacterium harboring pGFP-S65C was used for infection

${ }^{\mathrm{b}}$ Efficiency $=$ (Number of shoots with GFP fluorescence/total number of explants $) \times 100$. Each value represents mean \pm SD from three independent experiments

Fig. 4 sGFP-expressing transgenic plants introducing pIG-sGFP a Explants on kanamycin selective medium. Inoculated explants remained green on the medium containing kanamycin, whereas control explants without inoculation turned yellow and were finally dead. Bar, $10 \mathrm{~mm}$. b A GFPpositive shoot appears green under blue light due to GFP fluorescence. Bar, $5 \mathrm{~mm}$. c A non-transgenic shoot appears red under blue light due to the autofluorescence of chlorophyll. Bar, $5 \mathrm{~mm}$. d A putative transgenic $T_{0}$ plant growing in the greenhouse. e A fruit developed from a transgenic plant 40 days after self-crossing. Bar, $5 \mathrm{~cm}$
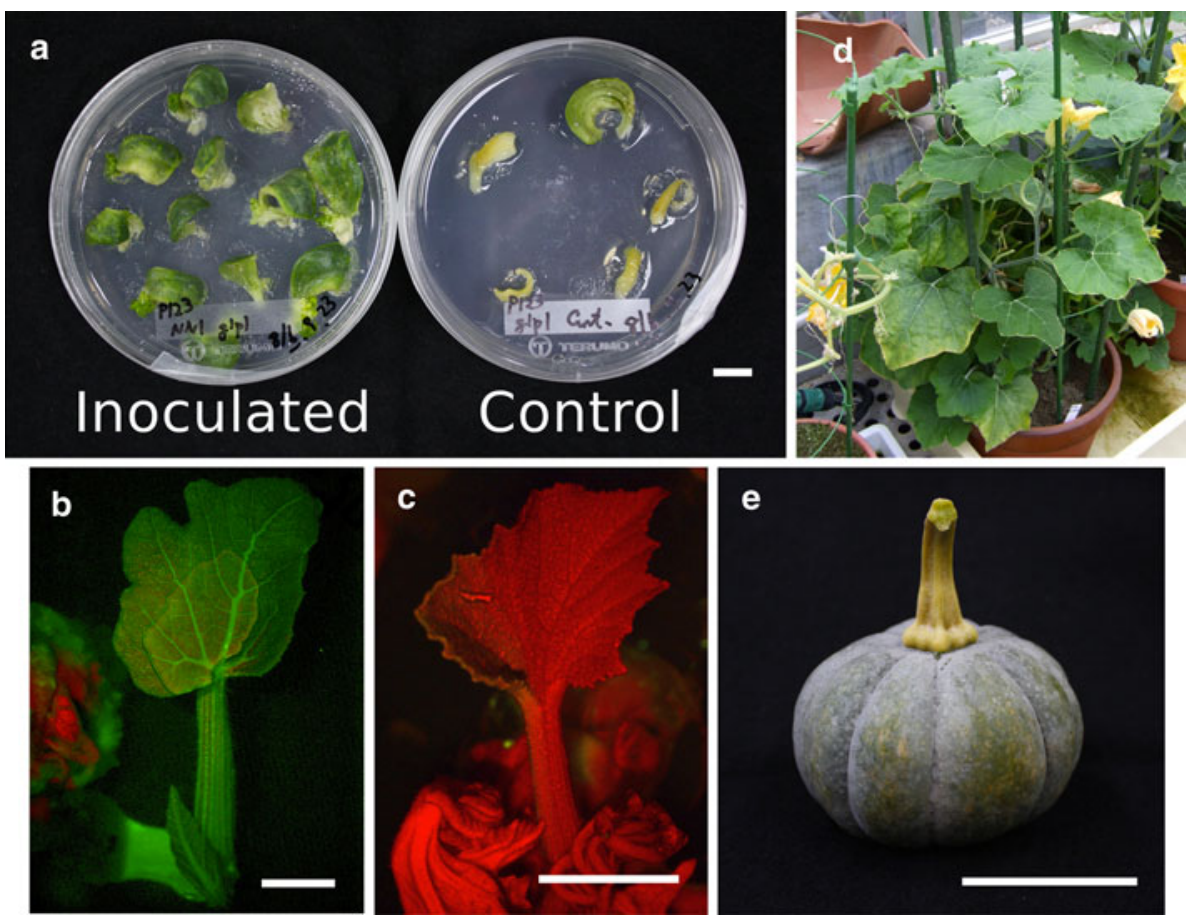

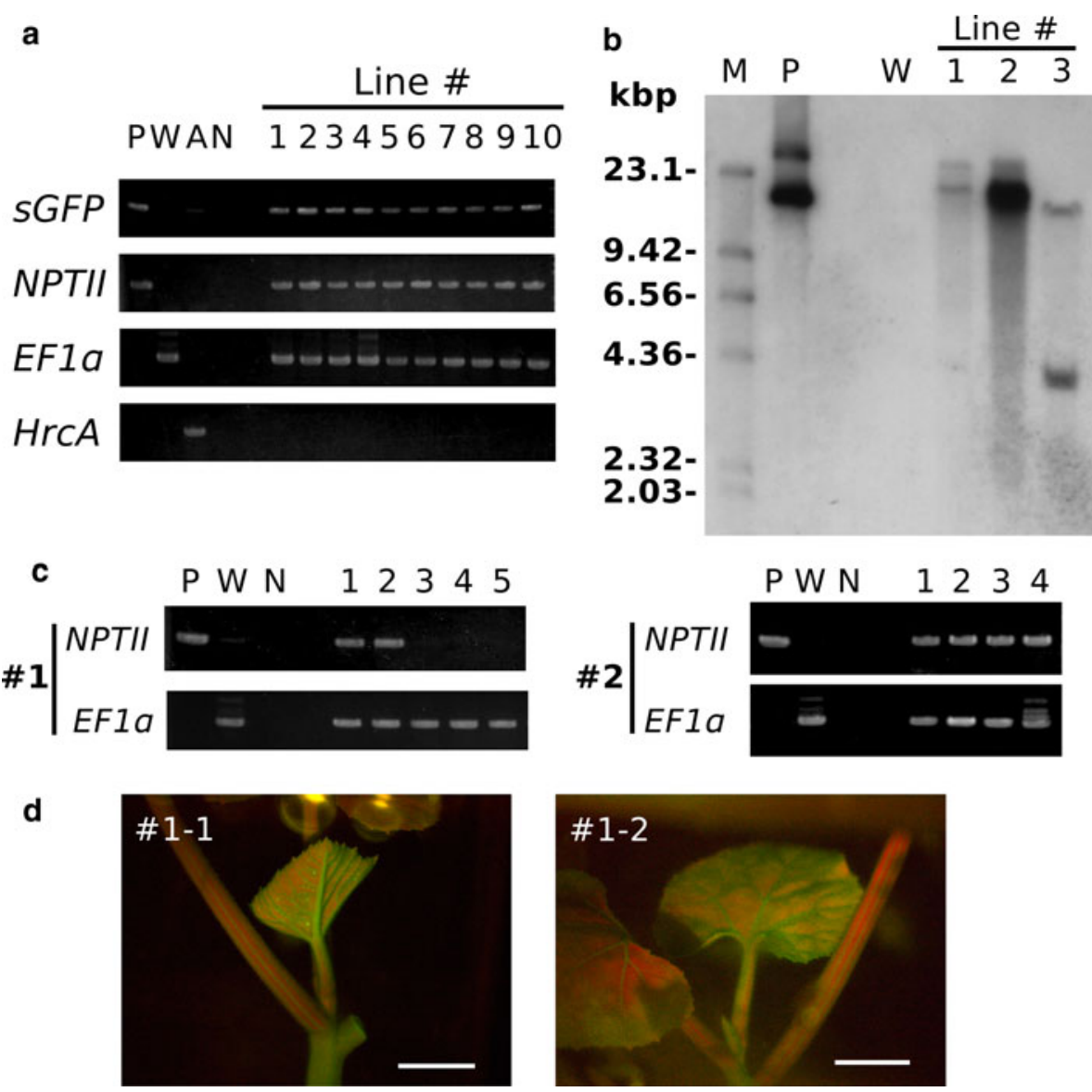

Fig. 5 Molecular analysis of transgenic plants introducing pIG-sGFP a $1.5 \%$ agarose gel electrophoresis of PCR-amplified DNA from leaf tissue of the regenerated shoots. Lane $W$ is the wild-type plant; Lane $P$ is pIG121-sGFP (positive control); Lane A is Agrobacterium genomic DNA; Lane $N$ is a mock without template DNA (negative control); Lanes $1-10$ are different independently regenerated shoots. Size of amplified DNA fragments of $s G F P, N P T I I, H r c A$, and $E F 1 \alpha$ were as follows, 720, 600, 980, and 600. b Southern blot analysis of genomic DNA from leaf tissues of selected transgenic plants, a vector, and a non-transgenic plant. Twenty $\mu \mathrm{g}$ of genomic DNA from each line was digested with HindIII, separated on $0.7 \%$ agarose gel, and transferred

to a nylon membrane. The membrane was hybridized with a DIGlabeled NPTII probe. Lane $W$ is the wild-type plant; Lane $P$ is pIG121-sGFP (positive control); Lane $M$ is DIG-labeled $\lambda /$ HindIII DNA marker (Roche Applied Science). c Genomic PCR analysis of NPTII in $\mathrm{T}_{1}$ plants. Lane $W$ is the wild-type plant; Lane $P$ is pIG121sGFP (positive control); Lane $N$ is a mock without template DNA (negative control); Lanes $1-5$ in \#1 and lane 1-4 in \#2 are independent $T_{1}$ progenies from each line. d GFP-positive shoots from the $T_{1}$ progenies of line \#1 appears green under blue light due to GFP fluorescence. Bar, $5 \mathrm{~mm}$

the junction of the stem and leaf petioles and did not have a negative effect on vitrification (data not shown). Agar concentration up to $2.0 \%$ and an air vent pot were useful for restoring vitrified shoots. Rooting was efficiently induced by adding $0.5 \mathrm{mg} / \mathrm{L}$ of indole acetic acid or naphthaleneacetic acid. Transformed plants grew normally in the greenhouse (Fig. 4d), and fruits were obtained by self-crossing (Fig. 4e).

\section{Analysis of transgenic plants}

To verify gene integration, genomic PCR analysis was performed for randomly selected putative transgenic plants for which sGFP fluorescence was observed (Fig. 4b). $E F 1 \alpha$, one of the famous housekeeping genes, was isolated

(GenBank accession No. AB615454) from C. moschata and used as a loading control. $s G F P$ was successfully amplified from ten randomly selected transgenic plants introducing pIG-sGFP (Fig. 5a). HrcA, which is widely distributed in Agrobacterium (Nakahigashi et al. 1999), was not amplified from the isolated genomic transgenic plant DNA, indicating no Agrobacterium contamination. To determine stable integration of the transgene into the plant genome, Southern blot analysis was performed on three randomly selected transgenic plants using a DIGlabeled NPTII probe (Fig. 5b). The NPT II probe hybridized to digested DNA from transgenic plants, but not to digested DNA from wild-type plants. Transgene inheritance was confirmed in $T_{1}$ generation plants using genomic PCR analysis. Amplification of NPTII was observed in the 
Fig. 6 Steps in the transformation of $C$. moschata Duch cv. Heiankogiku via direct shoot organogenesis from cotyledonary explants

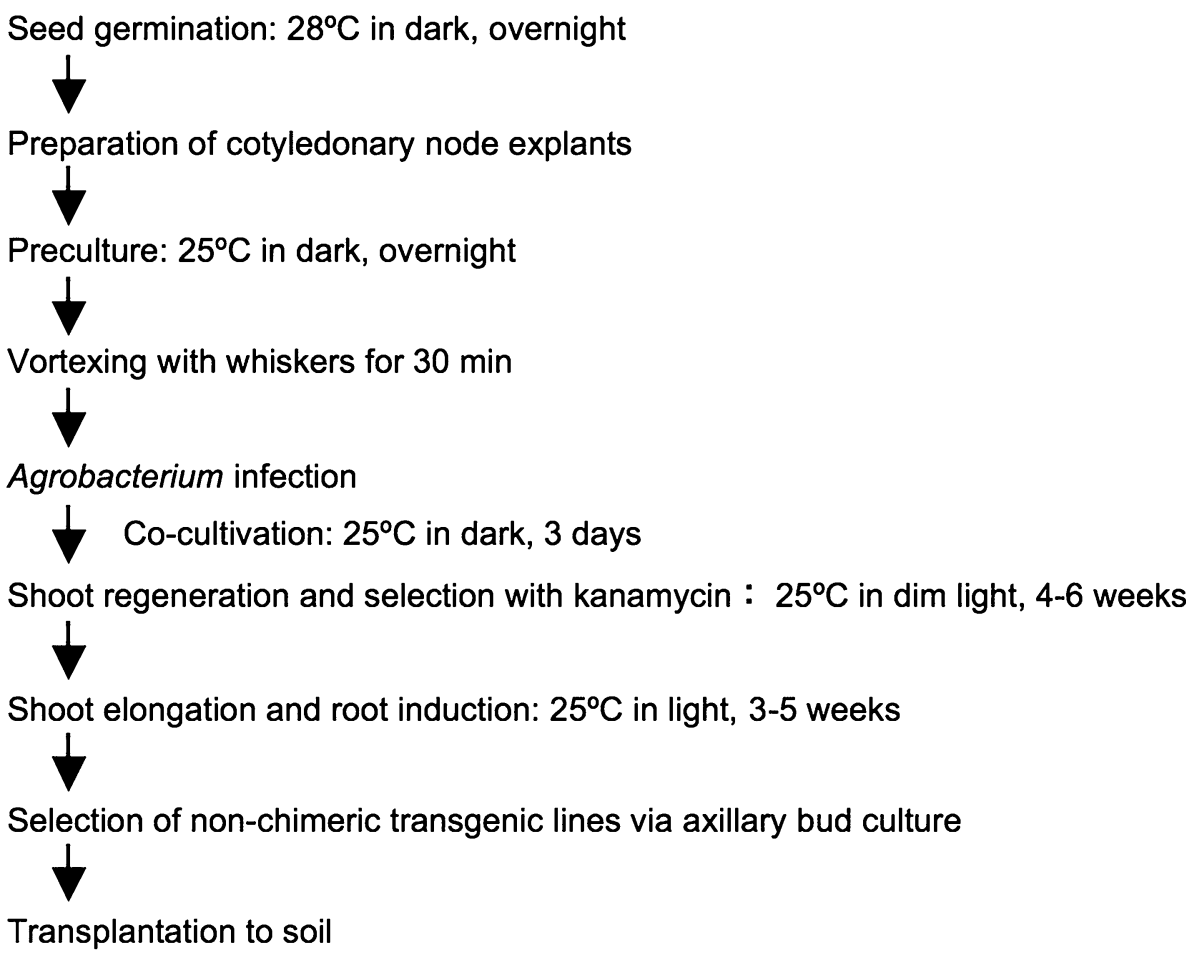

$\mathrm{T}_{1}$ generation plants (Fig. 5c), indicating successful transgene inheritance in the next generation. $T_{1}$ generations of line \#3 showed no transgene inheritance (data not shown), suggesting that line \#3 was a surface chimera plant (Schmulling and Schell 1993). Such plants were also observed in genetic transformations of cucumber (Konagaya et al., unpublished data). Finally, sGFP fluorescence was observed in $\mathrm{T}_{1}$ generation plants (Fig. 5d).

\section{Conclusion}

We established an efficient regeneration and transformation system for $C$. moschata (Fig. 6). This is the first report of efficient transformation via adventitious shoot organogenesis in $C$. moschata Duch. The average transformation efficiency was about $2.7 \%$ (Table 2). Wounding with a whisker suspension was the critical factor for producing transgenic kabocha squash plants. These results suggest that regenerated shoots may be developed in the lower cell layers of explants (Fig. 3c). The whiskers may help in the introduction of Agrobacterium into these lower cell layers. Despite it being over 7 years since the report of direct organogenesis of $C$. pepo using cotyledonary explants (Ananthakrishnan et al. 2003), to the best of our knowledge there has only been one report of successful transformation of a Cucurbita species (Shah et al. 2008). Whisker treatments may be applied for other important Cucurbita species, such as $C$. pepo and $C$. maxima because these species can regenerate via direct organogenesis using cotyledonary nodes (Ananthakrishnan et al. 2003; Lee et al. 2003). The transformation efficiency may remain a matter of improvement; however, the method we established will be applicable as a practical use. Progress in the molecular biology of Cucurbita species has been limited because of difficulties in genetic transformation, and this report should aid in molecular breeding experiments involving Cucurbita genera.

Acknowledgments The authors would like to thank Shikoku Chemicals Corporation (Kagawa, Japan) for generously providing "Albolex Y", the aluminum borate whiskers. The authors also wish to thank Mses. I. Kawaguchi, T. Tachibana, A. Sugai, Y. Ozeki, J. Shiota, and K. Masuda for their technical assistance. This work was supported by a Grant from the Ministry of Agriculture, Forestry and Fisheries of Japan (Integrated research project for plant, insect and animal using genome technology GMB-0002)

Open Access This article is distributed under the terms of the Creative Commons Attribution Noncommercial License which permits any noncommercial use, distribution, and reproduction in any medium, provided the original author(s) and source are credited.

\section{References}

Akama K, Shiraishi H, Ohta S, Nakamura K, Okada K, Shimura Y (1992) Efficient transformation of Arabidopsis thaliana: Comparison of the efficiencies with various organs, plant ecotypes and Agrobacterium strains. Plant Cell Rep 12:7-11

Akasaka-Kennedy Y, Tomita KO, Ezura H (2004) Efficient plant regeneration and Agrobacterium-mediated transformation via 
somatic embryogenesis in melon (Cucumis melo L.). Plant Sci 166:763-769

Akashi K, Morikawa K, Yokota A (2005) Agrobacterium-mediated transformation system for the drought and excess light stresstolerant wild watermelon (Citrullus lanatus). Plant Biotechnol $22: 13-18$

Ananthakrishnan G, Xia X, Elman C, Singer S, Paris HS, Gal-On A, Gaba V (2003) Shoot production in squash (Cucurbita pepo) by in vitro organogenesis. Plant Cell Rep 21:739-746

Asad S, Mukhtar Z, Nazir F, Hashmi JA, Mansoor S, Zafar Y, Arshad M (2008) Silicon carbide whisker-mediated embryogenic callus transformation of cotton (Gossypium hirsutum L.) and regeneration of salt tolerant plants. Mol Biotechnol 40:161-169

Chiu W, Niwa Y, Zeng W, Hirano T, Kobayashi H, Sheen J (1996) Engineered GFP as a vital reporter in plants. Curr Biol 6:325-330

Choi PS, Soh WY, Kim YS, Yoo OJ, Liu JR (1994) Genetictransformation and plant-regeneration of watermelon using Agrobacterium tumefaciens. Plant Cell Rep 13:344-348

Curuk S, Cetiner S, Elman C, Xia X, Wang Y, Yeheskel A, Zilberstein L, Perl-Treves R, Watad AA, Gaba V (2005) Transformation of recalcitrant melon (Cucumis melo L.) cultivars is facilitated by wounding with carborundum. Eng Life Sci 5:169-177

Damgaard O, Jensen LH, Rasmussen OS (1997) Agrobacterium tumefaciens-mediated transformation of Brassica napus winter cultivars. Transgenic Res 6:279-288

Dutt M, Grosser JW (2009) Evaluation of parameters affecting Agrobacterium-mediated transformation of citrus. Plant Cell Tiss Org 98:331-340

Edelstein M (2004) Grafting vegetable-crop plants: pros and cons. Acta Hort 659:235-238

Edwards K, Johnstone C, Thompson C (1991) A simple and rapid method for the preparation of plant genomic DNA for PCR analysis. Nucleic Acids Res 19:1349

Ezura H, Yuhashi KI, Yasuta T, Minamisawa K (2000) Effect of ethylene on Agrobacterium tumefaciens-mediated gene transfer to melon. Plant Breeding 119:75-79

Han JS, Kim CK, Park SH, Hirschi KD, Mok I (2005) Agrobacteriummediated transformation of bottle gourd (Lagenaria siceraria Standl.). Plant Cell Rep 23:692-698

He Z, Duan Z, Liang W, Chen F, Yao W, Liang H, Yue C, Sun Z, Dai J (2006) Mannose selection system used for cucumber transformation. Plant Cell Rep 25:953-958

Hulster A, Muller JF, Marschner H (1994) Soil-plant transfer of polychlorinated dibenzo-p-dioxins and dibenzofurans to vegetables of the cucumber family (Cucurbitaceae). Environ Sci Technol 28:1110-1115

Inui H, Wakai T, Gion K, Kim YS, Eun H (2008) Differential uptake for dioxin-like compounds by zucchini subspecies. Chemosphere 73:1602-1607

Jelaska S (1972) Embryoid formation by fragments of cotyledons and hypocotyls in Cucurbita pepo. Planta 103:278-280

Kathiravan K, Vengedesan G, Singer S, Steinitz B, Paris HS, Gaba V (2006) Adventitious regeneration in vitro occurs across a wide spectrum of squash (Cucurbita pepo) genotypes. Plant Cell Tiss Org 85:285-295

Lee YK, Chung WI, Ezura H (2003) Efficient plant regeneration via organogenesis in winter squash (Cucurbita maxima Duch.). Plant Sci 164:413-418

Mizuno K, Takahashi W, Ohyama T, Shimada T, Tanaka O (2004) Improvement of the aluminum borate whisker-mediated method of DNA delivery into rice callus. Plant Prod Sci 7:45-49

Murashige T, Skoog F (1962) A revised medium for rapid growth and bio assays with tobacco tissue cultures. Physiol Plantarum $15: 473-497$
Nakahigashi K, Ron EZ, Yanagi H, Yura T (1999) Differential and independent roles of a sigma(32) homolog (RpoH) and an HrcA repressor in the heat shock response of Agrobacterium tumefaciens. J Bacteriol 181:7509-7515

Oda M (2008) Use of grafted seedlings for vegetable production in Japan. Acta Hort 770:15-20

Ogawa Y, Mii M (2007) Meropenem and moxalactam: Novel betalactam antibiotics for efficient Agrobacterium-mediated transformation. Plant Sci 172:564-572

Olhoft PM, Somers DA (2001) L-Cysteine increases Agrobacteriummediated T-DNA delivery into soybean cotyledonary-node cells. Plant Cell Rep 20:706-711

Otani T, Seike N, Sakata Y (2007) Differential uptake of dieldrin and endrin from soil by several plant families and Cucurbita genera. Soil Sci Plant Nutr 53:86-94

Ozawa K (2009) Establishment of a high efficiency Agrobacteriummediated transformation system of rice (Oryza sativa L.). Plant Sci 176:522-527

Petolino JF, Hopkins NL, Kosegi BD, Skokut M (2000) Whiskermediated transformation of embryogenic callus of maize. Plant Cell Rep 19:781-786

Reichel C, Mathur J, Eckes P, Langenkemper K, Koncz C, Schell J, Reiss B, Maas C (1996) Enhanced green fluorescence by the expression of an Aequorea victoria green fluorescent protein mutant in mono- and dicotyledonous plant cells. Proc Natl Acad Sci USA 93:5888-5893

Schmulling T, Schell J (1993) Transgenic tobacco plants regenerated from leaf-disks can be periclinal chimeras. Plant Mol Biol 21:705-708

Shah P, Singh NK, Khare N, Rathore M, Anandhan S, Arif M, Singh RK, Das SC, Ahmed Z, Kumar N (2008) Agrobacterium mediated genetic transformation of summer squash (Cucurbita pepo L. cv. Australian green) with cbf-1 using a two vector system. Plant Cell Tiss Org 95:363-371

Smarrelli J, Watters MT, Diba LH (1986) Response of various Cucurbits to infection by plasmid-harboring strains of Agrobacterium. Plant Physiol 82:622-624

Suganuma K, Fujita T, Suzuki N, Niihara K (1990) Aluminum composites reinforced with a new aluminum borate whisker. J Mater Sci Lett 9:633-635

Tabei Y, Yamanaka H, Kanno T (1993) Adventitious shoot induction and plant regeneration from cotyledons of mature seed in watermelon (Citrullus lanatus L.). Plant Tissue Culture Letters 10:235-241

Tabei Y, Kitade S, Nishizawa Y, Kikuchi N, Kayano T, Hibi T, Akutsu K (1998) Transgenic cucumber plants harboring a rice chitinase gene exhibit enhanced resistance to gray mold (Botrytis cinerea). Plant Cell Rep 17:159-164

Toppi L, Pecchioni N, Durante M (1997) Cucurbita pepo L can be transformed by Agrobacterium rhizogenes. Plant Cell Tiss Org 51:89-93

Tricoli DM, Carney KJ, Russell PF, Mcmaster JR, Groff DW, Hadden KC, Himmel PT, Hubbard JP, Boeshore ML, Quemada HD (1995) Field-evaluation of transgenic squash containing single or multiple virus coat protein gene constructs for resistance to cucumber mosaic virus. Bio Technol 13:1458-1465

Vasudevan A, Selvaraj N, Ganapathi A, Choi CW (2007) Agrobacterium-mediated genetic transformation in cucumber (Cucumis sativus L.). Am J Biotechnol Biochem 3:24-32

Wang B, Liu LJ, Wang XX, Yang JY, Sun ZX, Zhang N, Gao SM, Xing XL, Peng DX (2009) Transgenic ramie [Boehmeria nivea (L.) Gaud.]: factors affecting the efficiency of Agrobacterium tumefaciens-mediated transformation and regeneration. Plant Cell Rep 28:1319-1327

White JC, Wang XP, Gent MPN, Iannucci-Berger W, Eitzer BD, Schultes NP, Arienzo M, Mattina MI (2003) Subspecies-level 
variation in the phytoextraction of weathered p,p'-DDE by Cucurbita pepo. Environ Sci Technol 37:4368-4373

Wu HW, Yu TA, Raja JAJ, Wang HC, Yeh SD (2009) Generation of transgenic oriental melon resistant to Zucchini yellow mosaic virus by an improved cotyledon-cutting method. Plant Cell Rep 28:1053-1064

Yamada T, Watanabe S, Arai M, Harada K, Kitamura K (2010) Cotyledonary node pre-wounding with a micro-brush increased frequency of Agrobacterium-mediated transformation in soybean. Plant Biotechnol 27:217-220

Zhang YF, Zhou JH, Wu T, Cao JS (2008) Shoot regeneration and the relationship between organogenic capacity and endogenous hormonal contents in pumpkin. Plant Cell Tiss Org 93:323-331 